\title{
Syllabic Length Effect in Visual Word Recognition by SLA Learners
}

\author{
Roya Ranjbar Mohammadi \\ Islamic Azad University of Bonab, Iran \\ E-mail: ranjbar_rroya@yahoo.com \\ Ali Akbar Ansarin (corresponding author) \\ University of Tabriz, Tabriz, Iran \\ PO Box 51665-347, University of Tabriz, Tabriz, Iran \\ E-mail: ansarin@tabrizu.ac.ir \\ Hadi Ziyadi \\ Azarbaijan University of Tarbiat Moallem \\ E-mail: Hadi.Ziyadi@yahoo.com
}

Received: 25-01-2014

doi:10.7575/aiac.ijalel.v.3n.4p.29
Accepted: 01-03-2014

Published: 01-07-2014

URL: http://dx.doi.org/10.7575/aiac.ijalel.v.3n.4p.29

\begin{abstract}
Studies on visual word recognition have resulted in different and sometimes contradictory proposals as Multi-Trace Memory Model (MTM), Dual-Route Cascaded Model (DRC), and Parallel Distribution Processing Model (PDP). The role of the number of syllables in word recognition was examined by the use of five groups of English words and nonwords. The reaction time of the participants to these words was measured using reaction time measuring software. The results indicated that there was syllabic effect on recognition of both high and low frequency words. The pattern was incremental in terms of syllable number. This pattern prevailed in high and low frequency words and non-words except in one syllable words. In general, the results are in line with the PDP model which claims that a single processing mechanism is used in both words and non-words recognition. In other words, the findings suggest that lexical items are mainly processed via a lexical route. A pedagogical implication of the findings would be that reading in English as a foreign language involves analytical processing of the syllable of the words.
\end{abstract}

Keywords: Multi-Trace Memory Model, Dual-Route Cascaded Model, Parallel Distribution Processing Model, Syllabic Effect, Word Recognition

\section{Introduction}

Cognitive mechanisms dealing with word recognition have received great attention in recent years (Ferrand \& New, 2003 and Balota et al., 2004). Different studies have focused on various components of word recognition and employed different models in their experiments.

One of the areas which is now of great importance and the result of which is used as a base in different experiments is the effect of word length on word recognition. Word length comprises different aspects such as the number of syllables, the number of letters, the number of morphemes and the number of phonemes. Among the mentioned components, the number of syllables has received greater attention (Ferrand, 2000; Klapp et al. 1973) and seems to be the most important issue in such studies. Majority of the studies conducted in the field of word recognition mainly have dealt with monosyllabic words and only a few have investigated processing of polysyllabic words, (Jared \& Seidenbergs, 1990). Word length effect on words and pseudo-words recognition in lexical decision task has been studied by different scholars from different perspectives. For example, Ziegler et al. (2001) reported that orthographic consistency determined not only the relative contribution of orthographic versus phonological codes within a given orthography but also the preferred grain size of units that are likely to be functional during reading. In another study, Spieler and Balota (1997) suggested that the word frequency plays less significant role alone as compared to the combined predictive power of frequency, neighborhood density, and orthographic length. Forster and Chambers (1973) examined lexical decision time for samples of words, non-words, and unfamiliar words and reported that naming time for words was shorter than for non-words, and that naming time for high frequency words was shorter than low frequency words. Still in another study, Content and Peereman (1992) and Ferrand (2000) showed that the number of syllables has an impact on low frequency words recognition and it does not have much to do with processing of high frequency words in word recognition.

Some of the studies that employed lexical decision and naming task reported no relationship between word length (number of the syllable) and word or non-word recognition (Hudson and Bergman, 1985). However, other scholars such 
as Spoehr and Smith (1973) proposed that syllable-size plays a crucial role in visual word recognition and claimed that words are processed syllable by syllable. Klapp (1971) also found that as the number of syllables increased in words, the response latency increased as well. In another study, Klaap, Anderson and Berrian (1973) found that as the number of syllables increase the reaction time increases significantly.

With a slight different focus, the relationship between syllable length and naming task has been evaluated (Ferrand \& New, 2003; Frederiksen \& Kroll, 1976; Richardson, 1976). Different theoretical models such as the Dual-Route Cascaded Model (Coltheart et al., 1993, 2001;), the PDP connectionist models (Harm \& Seidenberg, 1999; Plaut et al., 1996; Seidenberg \& McClelland, 1989) and the Multi-Trace Memory model (Ans et al., 1998) have been proposed for describing word recognition. Ferrand and New (2003) examined the effect of the number of syllables on naming latencies for non-words and very low-and high-frequency words. The results were supportive of syllabic effect for nonwords and low-frequency words but not for high frequency words. They also found that syllabic length affected very low frequency words in lexical decision task. This effect does not include high-frequency words and non-words in lexical decision task. Their results are more constant with Multiple-Trace Memory Model (MTM).

In following, the three main models (MTM, DRC and PDP) are briefly explained and the results of the related studies are analyzed to determine which model gives a credible explanation for the word recognition while reading.

\subsection{Alternative Models}

\subsubsection{Multi-Trace Memory Model (MTM)}

One of the implications of Multi-Trace Memory model, developed by Ans et al. (1998), was to deal with polysyllabic word reading. This model proposes two types of word processes namely holistic (global) and analytical. It is believed that these two processes do not work in parallel. It is claimed that global processing in word recognition always precedes analytical processing. As a result, learners first employ holistic processing in word recognition, and, if the process fails, they apply analytical route. If the orthographic output matches with the orthographic input, the phonological output is accepted as the global pronunciation of the input. This model also does not cover conversion rule (i.e. orthographic to phonological representation). MTM predicts that high frequency words will be processed holistically or lexically but low frequency words or non-words are recognized using analytical or non-lexical route. To investigate the case, syllable decomposition is allowed for low frequency and non-words. This model also does not assume any strategic use of these two different routes (holistic and analytical). Based on aforementioned characteristics, MTM proposes syllable as a unit of analysis.

\subsubsection{Dual-Route Cascaded Model (DRC)}

Dual-Route model is mainly proposed by Coltheart et al. (1993, 2001). In terms of processing polysyllabic word, DRC is similar to the MTM model in that it also postulates two processing types of Holistic and Analytical. DRC differs from the previous model in that it assumes that two processes work in parallel with each other. This means that, unlike the MTM model, learners employ two routes in processing words and non-words in a parallel manner and no route precedes or follows the other route. Another feature of the DRC model which makes it different from MTM is the presence of conversional rules. This model uses such rules at least for low frequency words or non-words. In terms of the predictive nature of the route application rule, the DRC model is similar to the MTM model in that it also predicts holistic or lexical route for high frequency words, and analytical and non-lexical route for low frequency words and non-words.

One of the main differences between MTM and DRC model is related to the strategic use of routes. In DRC model, it is assumed that if more and more words are encountered, the lexical (holistic) route would be emphasized and if nonwords occurrence increased the non-lexical route would be turned up. The unit of the analysis is graphemes/phonemes, and there is no syllabic decomposition in this model.

\subsubsection{Parallel Distribution Processing (PDP)}

Parallel Distribution Processing was developed by Jared and Seidenberg (1990). It deals with polysyllabic word recognition. PDP model proposes that a single mechanism is deployed in word recognition. So, unlike the previous models, it does not distinguish between holistic and analytical processing in word recognition. In terms of using the conversion rule, PDP is similar to MTM model in that it does not include such grapheme to phonemes conversion rules and it can process all types of words and non-words using word knowledge. Because PDP model assumes a single mechanism in word processing, it neither predicts any route for high and low frequency words nor proposes any strategic use of the different routes.

\subsubsection{MTM versus DRC and PDP}

Based on the characteristics of each model discussed above, we can now understand what each model would predict for different lexical items. In terms of lexical decision task, MTM predicts no length effect for high frequency words because it is believed that such words would be processed holistically, and word syllable length has no effects. But as it considers low frequency words to be processed analytically, syllabic effect is assumed to be the determining factor in low frequency words; hence, it predicts that as the number of syllable increases its processing time increases. This model also predicts no syllabic effect for non-words. DRC model like MTM model believes in no syllabic effect for high frequency words and non-words, but it assumes that if grapheme-phonemes are replaced by graghemic syllables and phonemic syllables, they would influence word recognition of low frequency words. PDP model also assumes no 
syllabic effects on high frequency words and non-words, but it predicts that syllabic length would influence word recognition in low frequency words.

\subsubsection{Purpose of the study}

In this study, we wanted to focus on word length components effects on second language word recognition. We mainly concentrated on syllabic effect. We wanted to see whether the number of the syllables influences the way a word is recognized by second language students. In the previous experiments, words and non-words had been presented in separate groups, so participants knew in advance whether the stimuli would be a word or a non-word, but in the present study, we presented the words and non-words randomly. Precisely, researchers intended to answer two main questions:

RQ1: Does the number of the syllable influence word recognition in words and non-words?

RQ2: Do students use analytical or holistic processing in recognition of words and non-words with different syllables?

\section{Methodology}

\subsection{Participants}

Thirty six undergraduate English language students took part in the experiment. All participants spoke Azeri as their native language and English as their foreign language. The two languages have different orthographic systems. The participants use the Perso-Arabic script as formal writing system. We expected that participants' first language would not have any effect on their second language word recognition. They were BA final students of English as a foreign language. The age range of the participants was 19-23. All volunteered to participate in the experiment and all had normal or corrected-to-normal vision.

\subsection{Material}

A set of 150 English words were selected based on frequency and the number of syllables as stimuli in the experiment. These stimuli were real English words. Another 150 non-words were generated by distorting the letters of the selected words. This list was generated as non-words by distorting the words through inverting second and third letter from beginning of words with less than 7 letters. For words with more than 7 letters also we inverted the second and third letters from end of the words, simply just not to distort beginning and end of the words. All of the non-words had straightforward and unambiguous pronunciation following English spelling-to-sound translation rule. In selecting words we considered two factors, a) word frequency and b) number of syllables based on the corpus. These words were divided into two main groups of high frequency and low frequency words. Then each main group was divided into five subgroups of 1 to 5 syllables. We selected 15 words for each subgroup ( 75 words as high frequency words and 75 words as low frequency words). We also generated the distorted form of all the words and created other 10 groups for non-words (5 groups for high frequency distorted words and 5 groups for low frequency distorted words). Based on Corpus of Contemporary American English (2012) all high frequency words were ranked and listed as the top 1500 and low frequency words were ranked 2000 up to 4000 . See the appendix for the details.

\subsection{Procedures}

The stimuli were displayed in lowercase on the computer screen using Mind Reaction Time Saver (MRTS) software. Each participant was tested individually in the laboratory setting. Before starting the experiment, detailed instruction was given to each participant. In the experiment, the stimuli remained on the screen for 3 second until the participant responded by pressing a key on the keyboard for the word and another key for the non-word. Reaction time was measured automatically from stimulus onset till the participants' response. MRTS software was used for presenting the stimuli and measuring the reaction time. The inter-trail interval was 1 second. Stimulus was presented in different lists and words were randomly assigned to each list. So each list included high frequency words, low frequency words, high frequency non-words and low frequency non-words. The overall time of the experiment was approximately 40 minutes. The experiment was done in two sessions. Each session lasted for about 20 minutes.

The participants' reaction time to word recognition was measured for each group separately. The reaction time (RT) was trimmed applying a 3000-ms cutoff. We also omitted RT below 300-ms. Overall, we had 4 types of analysis. Two were related to comparing high and low frequency 1,2,3,4 and 5 syllable words. The same analysis was applied for high and low non-words $(1,2,3,4,5$ syllable). Precisely speaking, the two factors for the analysis were lexicality (high frequency and low frequency word and non-word) and number of syllables (two, three, four and five).

\section{Results}

The mean reaction time for all participants in lexical decision task is presented in Table 1. As shown in Table 2 the pvalues of the t-test for comparing high frequency words with different number of syllables were less than 0.05 . That is the mean reaction times of the syllables were significantly different. As a result, it could be concluded that there was syllabic effect on word recognition. The same results were observed in the case of low frequency words, as summarized in Table 3. It took longer time to recognize words with more syllables than words with less syllables both in high and low frequency words. 
Table 1. Descriptive statistics for high and low frequency words

\begin{tabular}{lllllll}
\hline \multirow{2}{*}{ Syllable } & & $\mathrm{N}$ & \multicolumn{2}{l}{ High frequency words } & & \multicolumn{2}{l}{ Low frequency words } \\
\cline { 6 - 7 } & & Mean & Std & & Mean & Std \\
\hline One & 15 & 1.107 & 0.189 & & 1.168 & 0.183 \\
Two & 15 & 1.357 & 0.222 & & 1.365 & 0.251 \\
Three & 15 & 1.510 & 0.276 & & 1.620 & 0.250 \\
Four & 15 & 1.652 & 0.275 & & 1.773 & 0.244 \\
Five & 15 & 1.777 & 0.291 & & 1.969 & 0.72 \\
\hline
\end{tabular}

Table 2. T-test comparing high frequency words in terms of number of syllables

\begin{tabular}{lllll}
\hline Syllable Pairs & Std. Error Mean & $\mathrm{t}$ & $\mathrm{df}$ & Sig.(2-tailed) \\
\hline One vs. Two syllable & 0.0201 & -12.418 & 35 & 0.000 \\
Two vs. Three syllable & 0.0313 & -4.857 & 35 & 0.000 \\
Three vs. Four syllable & 0.0317 & -4.471 & 35 & 0.000 \\
Four vs. Five syllable & 0.0303 & -4.134 & 35 & 0.000 \\
\hline
\end{tabular}

Table 3. T-test comparing low frequency words in terms of number of syllables

\begin{tabular}{lllll}
\hline Pair & Std. Error Mean & $\mathrm{t}$ & $\mathrm{df}$ & Sig.(2-tailed) \\
\hline One vs. Two syllable & 0.0264 & -7.424 & 35 & 0.000 \\
Two vs. Three syllable & 0.0498 & -5.113 & 35 & 0.000 \\
Three vs. Four syllable & 0.0376 & -4.080 & 35 & 0.000 \\
Four vs. Five syllable & 0.0510 & -3.843 & 35 & 0.000 \\
\hline
\end{tabular}

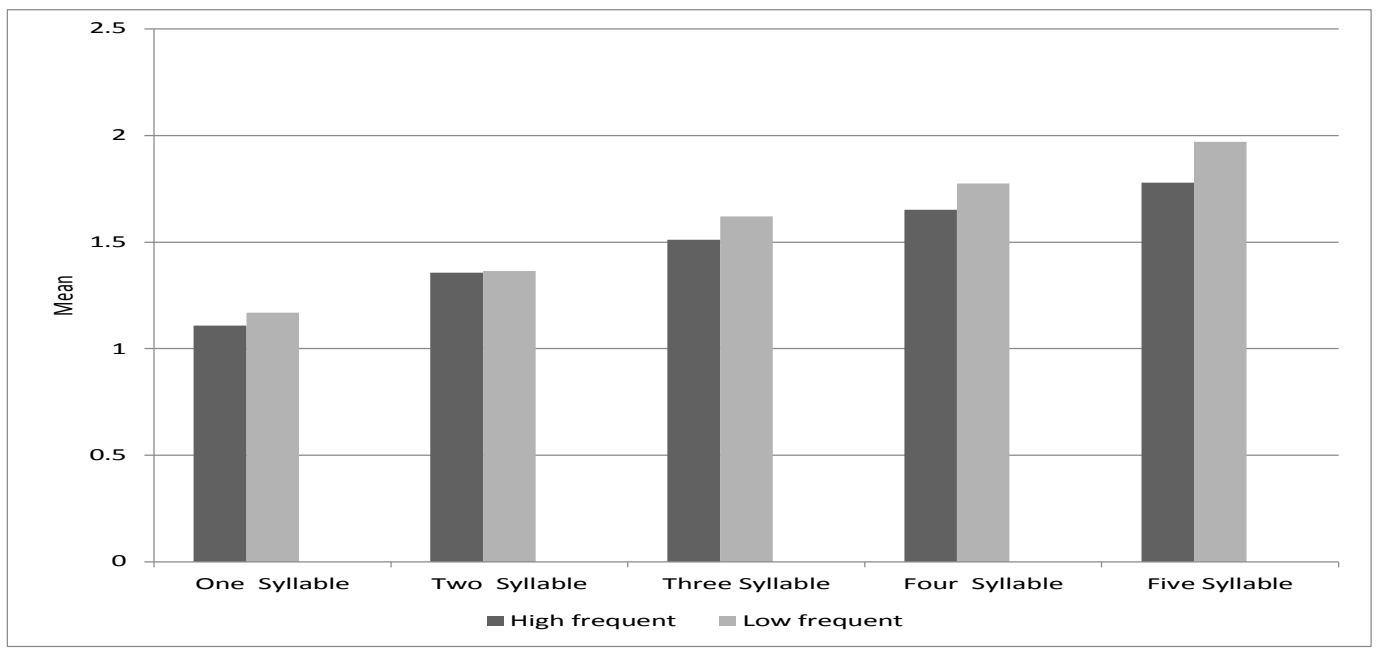

Figure 1. Mean reaction time for high and low frequency words

As indicated in Tables 2 and 3, in the case of words, there was no effect of word frequency on reaction time. Figure 1 illustrates the mean reaction time for both high and low frequency words. As shown, the reaction time increased in accordance with the increase of number of syllables.

The descriptive statistics regarding high and low frequency non-words is presented in Table 4. The mean of reaction for low frequency non-words was less when compared to corresponding high frequency non-words in each category. 
Table 4. Descriptive statistics regarding high and low frequency non-words

\begin{tabular}{lllllll}
\hline \multirow{2}{*}{ Syllable } & & \multicolumn{2}{l}{ High frequency non-words } & & \multicolumn{2}{l}{ Low frequency non-words } \\
& & Mean & Std & & Mean & Std \\
\hline One & 15 & 1.154 & 0.236 & & 1.148 & 0.238 \\
Two & 15 & 1.194 & 0.241 & & 1.178 & 0.239 \\
Three & 15 & 1.260 & 0.276 & & 1.154 & 0.209 \\
Four & 15 & 1.289 & 0.275 & & 1.399 & 0.343 \\
Five & 15 & 1.547 & 0.291 & & 1.627 & 0.338 \\
\hline
\end{tabular}

Table 5. T-test comparing high frequency non-words in terms of the number of syllables

\begin{tabular}{lllll}
\hline Pair & Std. Error Mean & $\mathrm{t}$ & $\mathrm{df}$ & Sig.(2-tailed) \\
\hline One vs. Two syllable & 0.0238 & -1.654 & 34 & 0.107 \\
Two vs. Three syllable & 0.0238 & -3.254 & 34 & 0.003 \\
Three vs. Four syllable & 0.0321 & -4.294 & 34 & 0.000 \\
Four vs. Five syllable & 0.0348 & -3.942 & 34 & 0.000 \\
\hline
\end{tabular}

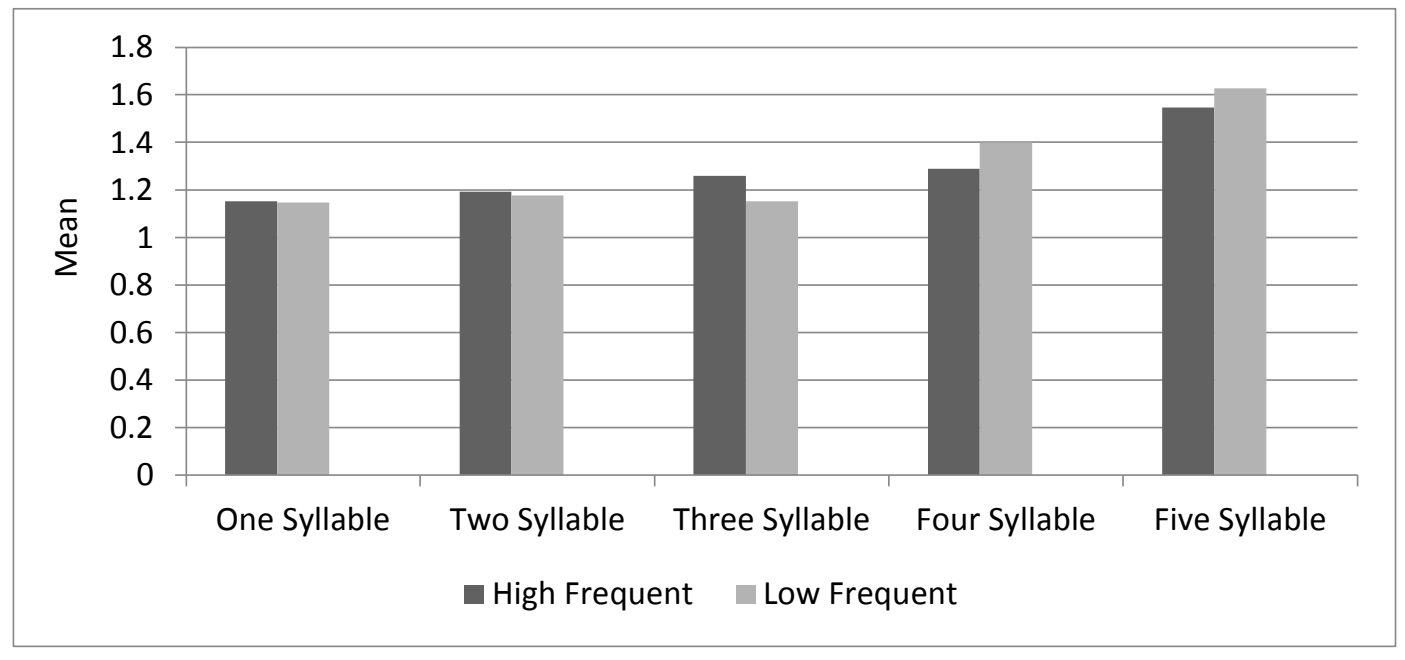

Figure 2. Mean reaction time for high and low frequency non-words

As depicted in Figure 2, the reaction time for low frequency non-words was less for one to three syllables categories but slightly higher for four syllable and five syllable words. To examine the significance of this difference a t-test was run.

Table 6. T-test comparing low frequency non-words in terms of number of syllables

\begin{tabular}{lllll}
\hline Pair & Std. Error Mean & $\mathrm{t}$ & $\mathrm{df}$ & Sig.(2-tailed) \\
\hline One vs. Two syllable & 0.0370 & -0.801 & 34 & 0.428 \\
Two vs. Three syllable & 0.0392 & 0.620 & 34 & 0.050 \\
Three vs. Four syllable & 0.0570 & -4.297 & 34 & 0.000 \\
Four vs. Five syllable & 0.0778 & -2.930 & 34 & 0.006 \\
\hline
\end{tabular}

The subsequent tables (Table 5 and Table 6) show that there was no significant difference between 1 and 2 syllable nonwords, as the significance levels are less than 0.05 in all cases except one vs. two syllable non-words. In other words, increasing the number of the syllables in non-words did not lead to significant difference in the reaction time between 1 and 2 syllable non-words. But for both high and low frequency non-words, there were significant differences between 2 \& 3, $3 \& 4$, and $4 \& 5$ Syllable non-words. 


\section{Discussion and Conclusions}

The major goal of this study was to determine the role of length of a word, in general, and the number of syllables in a word in its recognition by the second language learners. As discussed earlier in the previous experiments, words and non-words had been presented separately to participants. This might alert the participants in advance about the nature of stimuli i.e. being a word or a non-word. However, in the present study, a random method was used to present the words and non-words to the participants in order to find the answers to the research questions of the study.

4.1.Responding to the research questions

\subsubsection{Research question 1}

Does the number of the syllable influence word recognition in words and non-words?

The results of the experiment showed an interaction between lexicality (high-frequency words, low-frequency words, non-words) and the number of syllables (i.e., one, two, three, four, and five). More specifically, the number of syllables influenced RT for high and low-frequency words and non-words, except for 1 vs. 2 syllable non-words. For non-words with 2 vs. 3,3 vs. 4 and 4 vs. 5 syllables that comparison showed significant differences. This does not replicate the results obtained in two different experiments by Ferrand (2000) and Ferrand and New (2003).

In this study, the items were presented in a mixed list (high-frequency words, low-frequency words, and non-words) as opposed to the previous experiments conducted by Ferrand (2000); participants could not predict whether an item would be a word or a non-word prior to its presentation. Under such a condition, the use of the non-lexical route (analytic procedure) may have been maximized and the use of the lexical route (global procedure) minimized, if these were under strategic control. Accordingly, the obtained results on the word frequency and number of syllables are in contrast with the results reported by Ferrand (2000). Therefore, it seems that these two procedures are not under strategic control. In fact, the MTM model of polysyllabic word reading (Ans et al., 1998) obviously states that these two routes are not under strategic control, whereas the DRC model claims that they are (Coltheart et al., 2001). According to the DRC model, "as more and more non-words are encountered, the readers turn down the lexical route (because it is never providing a correct response) or turn up the non-lexical route (because it is always providing the correct response), or both". So, these non-strategic uses of lexical and non-lexical routes in word recognition are more consistent with MTM model.

However, the results are not totally in accordance with the predictions made by the MTM model (Ans et al., 1998) on reading polysyllabic words and non-words as this model advocates the syllabic effect for low-frequency words and nonwords. Precisely speaking, the findings of the study show that there is syllabic effect for both high and low frequency word and non-words.

\subsubsection{Research question 2}

Do students use analytical or holistic processing in recognition of words and non-words with different syllables?

In the spirit of conclusion, according to the holistic or lexical route, word shape is considered to be a determining factor in word recognition. So RT should not increase by the increase in the letters or syllables of the words, because participants would use each word's unique shape in its recognition. On the other hand, analytical or non-lexical approach suggests that sub-lexical units are analyzed in word recognition (e.g. syllable, letter, morpheme and phoneme). In so doing if we increase the number of sub-lexical units, RT will increase. The latter trend was observed in the present study. The corollary of this view is that participants used analytical processing in word recognition.

The findings are consistent with the claims of Parallel Distribution Processing model as it assumes that there is a single process for all high and low frequency words and non-words. As our results suggest, a single mechanism is used for recognition of high and low words and non-words.

All in all, our results suggest that reading in the foreign language involves analytical procedure for high and low frequency words and for non-words, and that the syllable constitutes an important unit of reading in English.

\section{References}

Ans, B., Carbonnel, S., \& Valdois, S. (1998). A Connectionist Multiple-Trace Memory Model for Polysyllabic Word Reading. Psychological Review, 105, 678-723.

Balota, D. A., Cortese, M. J., Sergent-Marshall, S. D., Spieler, D. H., \& Yap, M. J., (2004). Visual Word Recognition of Single-Syllable Words. Journal of Experimental Psychology: General. 133 (2), 283-316.

Coltheart, M., Curtis, B., Atkins, P., \& Haller, M. (1993). Models of Reading Aloud: Dual-Route and ParallelProcessing-Distributed Approaches. Psychological Review, 100, 589-608.

Coltheart, M., Rastle, K., Perry, C., Langdon, R., \& Ziegler, J. (2001). DRC: A Dual Route Cascaded Model of Visual Word Recognition and Reading Aloud. Psychological Review, 108(1), 204-256.

Content, A., \& Peereman, R. (1992). Single and multiple process models of print to speech conversion. In J. Alegria, D. Holender, J. Morais, \& M. Radeau (Eds.), Analytic approaches to human cognition (pp. 213-236). Amsterdam: Elsevier.

Corpus of Contemporary American English. (2012). 450 MILLION WORDS, Retrieved from http://corpus.byu.edu/. 
Ferrand, L. (2000). Reading Aloud Polysyllabic Words and Nonwords: The Syllabic Length Effect Reexamined. Psychonomic Bulletin \& Review, 7(1), 142-148.

Ferrand, L., New, B., (2003). Syllabic Length Effects in Visual Word Recognition and Naming. Acta Psychologica. 113 (2), 167-183.

Frederiksen, J. R., \& Kroll, J. F. (1976). Spelling and Sound: Approaches to the Internal Lexicon. Journal of Experimental Psychology: Human Perception and Performance, 2, 361-379.

Forster, K. I., \& Chambers, S. (1973). Lexical Access and Naming Time. Journal of Verbal Learning and Verbal Behavior, 12, 627-635.

Harm, M.W., Seidenberg, M. S. (1999). Phonology, Reading Acquisition and Dyslexia: Insights from Connectionist Models. Psychological Review. 106, 491-528.

Hudson, P. T. W., Bergman, M. W. (1985). Lexical Knowledge in Word Recognition: Word Length and Word Frequency in Naming and Lexical Decision Tasks. Journal of Memory and Language. 24, 46-58.

Jared, D., \& Seidenberg, M. S. (1990). Naming Multisyllabic Words. Journal of Experimental Psychology: Human Perception and Performance, 16, 92-105.

Klapp, S. T. (1971). Implicit Speech Inferred from Response Latencies in Same-Different Decisions. Journal of Experimental Psychology, 91, 262-267.

Klapp, S. T., Anderson, W. G., \& Berrian, R. W. (1973). Implicit Speech in Reading Reconsidered. Journal of Experimental Psychology, 100, 368-374.

Plaut, D.C., McClelland, J. L., Seidenberg, M. S., \& Patterson, K. (1996). Understanding Normal and Impaired Word Reading: Computational Principles in Quasi-Regular Domains. Psychological Review. 103, 56-115.

Richardson, J. T. E. (1976). The Effect of Stimulus Attributes upon Latency of Word Recognition. Br. Journal of psychology. 67, 315-325.

Seidenberg, M. S., \& McClelland, J. L. (1989). A Distributed, Developmental Model of Visual Word Recognition and Naming. Psychological Review, 96, 523-568.

Spieler, D. H., Balota, D. A. (1997). Bringing Computational Models of Word Naming down to the Item Level. Psychological Science. 8, 411-416.

Spoehr, K. T., \& Smith, E. E. (1973). The Role of the Syllables in Perceptual Grouping. Cognitive Psychology, 5, 7189.

Ziegler, J. C., Perry, C., Jacobs, A. M., \& Braun, M. (2001). Identical Words are Read Differently in Different Languages. Psychological Science. 12 (5), 379-384.

\begin{tabular}{llllll}
$\begin{array}{l}\text { Appendix } \\
\text { List of the words }\end{array}$ & and nonwords & & & & \\
\hline High frequent & Distorted form & Syllable & Low frequency & Distorted form & Syllable \\
\hline Group & Gorup & 1 & Pace & Pcae & 1 \\
Great & Gerat & 1 & Chart & Chrat & 1 \\
First & Frist & 1 & Rice & Rcie & 1 \\
House & Huose & 1 & Hold & Hlod & 1 \\
Find & Fnid & 1 & Belt & Blet & 1 \\
Know & Konw & 1 & Tight & Tgiht & 1 \\
Born & Bron & 1 & Bone & Bonne & 1 \\
Fresh & Fersh & 1 & Sand & Snad & 1 \\
Bring & Birng & 1 & Card & Crad & 1 \\
Store & Sotre & 1 & False & Flase & 1 \\
Mind & Mnid & 1 & Pack & Pcak & 1 \\
White & Wihte & 1 & Lock & Lcok & 1 \\
Warm & Wram & 1 & Fist & fsit & 1 \\
Work & Wrok & 1 & Pitch & Ptich & 1 \\
Ground & Gorund & 1 & Port & Prot & 1 \\
\hline
\end{tabular}




\begin{tabular}{llllll}
\hline High frequent & Distorted form & Syllable & Low frequent & Distorted form & Syllable \\
\hline River & Rvier & 2 & Create & Craete & 2 \\
Notice & Ntoice & 2 & Hero & Hreo & 2 \\
Movement & Mvoemnet & 2 & Tiny & Tniy & 2 \\
Problem & Porblem & 2 & Consist & Cnosist & 2 \\
Reason & Raeson & 2 & Version & Vresion & 2 \\
Purpose & Prupose & 2 & Conflict & Cnoflict & 2 \\
Between & Bteween & 2 & Mountain & Muontian & 2 \\
Accept & Acecpt & 2 & Emotion & Eomtion & 2 \\
Proper & Porper & 2 & Uniform & Uinfrom & 2 \\
Business & Bsuinses & 2 & Powder & pwoder & 2 \\
Public & Pbulic & 2 & Storage & sotrage & 2 \\
Empty & Etmpy & 2 & Weekend & Wekeend & 2 \\
Member & Mebmer & 2 & Eager & Eagear & 2 \\
Present & Persent & 2 & Silver & Sivler & 2 \\
Moment & Moemnt & 2 & Inverse & Ivnerse & 2 \\
\hline
\end{tabular}

\begin{tabular}{|c|c|c|c|c|c|}
\hline High frequent & Distorted form & Syllable & Low frequency & Distorted form & Syllable \\
\hline Situation & Stiuatoin & 3 & Comfortable & Cmofortalbe & 3 \\
\hline Consider & Cnosiedr & 3 & Discipline & Dsiciplnie & 3 \\
\hline Newspaper & Nwespaepr & 3 & Medicine & mdeicnie & 3 \\
\hline Probably & Porbalby & 3 & Register & Rgeisetr & 3 \\
\hline Opposite & Opopstie & 3 & Investment & Ivnestmnet & 3 \\
\hline Determine & Detremine & 3 & Calendar & Claendar & 3 \\
\hline Important & Ipmortnat & 3 & Element & Eelment & 3 \\
\hline Secretary & Sceretray & 3 & Contrary & Cnortrary & 3 \\
\hline Influence & Ifnluecne & 3 & Gentleman & Gnetleamn & 3 \\
\hline Regular & rgeular & 3 & Mechanism & Mcehansim & 3 \\
\hline Necessary & Ncessray & 3 & Institute & Isntiute & 3 \\
\hline Develop & Dveleop & 3 & Regional & Rgeioanl & 3 \\
\hline Hospital & Hsopiatl & 3 & Democrats & Dmeocrtas & 3 \\
\hline Character & Chracter & 3 & Assumption & Asusmptoin & 3 \\
\hline Condition & Cnoditoin & 3 & Distinguished & Dsitinguisehd & 3 \\
\hline
\end{tabular}




\begin{tabular}{|c|c|c|c|c|c|}
\hline High frequency & Distorted form & Syllable & Low frequency & Distorted form & Syllable \\
\hline Information & Ifnormatoin & 4 & Academic & Acdaeimc & 4 \\
\hline Experience & Epxeriecne & 4 & Automatic & Atuomaitc & 4 \\
\hline Development & Dveleopment & 4 & Transportation & Tarnsportatoin & 4 \\
\hline Political & Ploitiacl & 4 & Encouragement & Ecnouragemnet & 4 \\
\hline Environment & Evnironmnet & 4 & Entertainment & Etnertainmnet & 4 \\
\hline Particular & Praticualr & 4 & Recommended & Rceomenedd & 4 \\
\hline University & Uinverstiy & 4 & Complicated & Cmoplicaetd & 4 \\
\hline Temperature & Tmeperatrue & 4 & Contribution & Cnotributoin & 4 \\
\hline Education & Eudcatoin & 4 & Consequently & Cnosequenlty & 4 \\
\hline Manufacture & Mnaufactrue & 4 & Fundamental & Fnudamenatl & 4 \\
\hline Approximate & Aprpoximtae & 4 & Availability & Avialbiltiy & 4 \\
\hline Especially & Epsecilaly & 4 & Vocabulary & Vcoabulray & 4 \\
\hline Considerably & Cnosideralby & 4 & Consideration & Cnosideratoin & 4 \\
\hline Application & Aplpicatoin & 4 & Embarrassment & Ebmarrassmnet & 4 \\
\hline Population & Pouplatoin & 4 & Satisfaction & Staisfactoin & 4 \\
\hline
\end{tabular}

\begin{tabular}{llllll}
\hline High frequency & Distorted form & Syllable & Low frequency & Distorted form & Syllable \\
\hline Qualification & Qaulificatoin & 5 & Enthusiastic & Etuhusiasitc & 5 \\
Immediately & Imemdiatley & 5 & Automatically & Atuomatiaclaly & 5 \\
Opportunity & Opoprtuntiy & 5 & Identification & Iedntificatoin & 5 \\
Administration & Amdinistratoin & 5 & Agricultural & Argicultuarl & 5 \\
Organization & Oogranizatoin & 5 & Simultaneously & Smiultaneoulsy & 5 \\
Incomprehension & Icnomprehensoin & 5 & Incomparable & Icnomparalbe & 5 \\
Traditionally & Tarditionlaly & 5 & Subordination & Sbuordinatoin & 5 \\
Individuals & Idnividulas & 5 & Classification & Calssificatoin & 5 \\
Approximately & Aprproximatley & 5 & Incompetency & Icnompetecny & 5 \\
International & Itnernatioanl & 5 & Constitutional & Cnostitutioanl & 5 \\
Similarity & Smiliarity & 5 & Recommendation & Rceommendatoin & 5 \\
Congratulation & Cnogratulatoin & 5 & Discrimination & Dsicriminatoin & 5 \\
Representation & Rperesentatoin & 5 & Civilization & Cviilizatoin & 5 \\
Creativity & Cerativtiy & 5 & Intermediate & Itnermeditae & 5 \\
Investigation & Ivnestigatoin & 5 & Universality & Uinversaltiy & 5 \\
\hline
\end{tabular}

